\title{
Extension of the process limits in laser beam welding of thick-walled components using the Laser Multi-Pass Narrow-Gap welding (Laser-MPNG) on the example of the nickel-based material Alloy 617 occ
}

\author{
Benjamin Kessler ${ }^{1} \cdot$ Dirk Dittrich $^{1} \cdot$ Berndt Brenner $^{1} \cdot$ Jens Standfuss $^{1} \cdot$ Christoph Leyens $^{1,2}$
}

Received: 30 September 2020 / Accepted: 16 March 2021 / Published online: 15 April 2021

(C) The Author(s) 2021

\begin{abstract}
The joining of thick-walled components using beam-based joining techniques is content of worldwide research and development activities, but has not yet been established in industry. State of the art to weld nickel super alloys is currently a TIG narrow-gap welding. The present paper is focusing on a new specific laser beam welding process, the so-called Laser Multi-Pass Narrow-Gap welding (Laser-MPNG). It first explains the process principle based on 2D beam oscillation, the use of fiber lasers and the multipass principle. The potential of the Laser-MPNG welding process is demonstrated using the technically significant nickel-based material Alloy 617 occ. As a result, it was possible for the first time to realize a weld with a wall thickness of $140 \mathrm{~mm}$ free of cracks or bonding defects. Promising results of creep and low-cycle fatigue tests are used to show the potential that Laser-MPNG welded joints would have for future industrial applications.
\end{abstract}

Keywords Laser beam welding $\cdot$ Laser-MPNG $\cdot$ Nickel-base material $\cdot$ Alloy 617 occ $\cdot$ Multi-pass

\section{Introduction}

Investigations on the feasibility of multi-pass laser beam welding (LBW) showed that sheet thicknesses of up to $100 \mathrm{~mm}[23]$ are joinable in the laboratory. Two process approaches were pursued:

I. Oscillation of the laser beam by motor movement of the laser material processing head or manipulation of the laser beam with mirrors or

II. defocusing the laser beam to control the power density.

Recommended for publication by Commission IV - Power Beam Processes

Benjamin Kessler

benjamin.kessler@iws.fraunhofer.de

1 Fraunhofer Institute for Material and Beam Technology IWS Dresden, Dresden, Germany

2 Technische Universität Dresden, Institute of Materials Science, Dresden, Germany
The materials investigated range from mild steels [15], stainless steels [10], aluminum alloys [3], or nickel-based alloys [17]. Fiber and disk lasers with maximum powers up to $16 \mathrm{~kW}$ are most frequently used for the development. However, the actual power used during welding does not exceed $9 \mathrm{~kW}$. The beam diameters vary from 300 to $700 \mu \mathrm{m}$, whereby significantly larger beam diameters are used in the effective zone due to defocusing. Typical welding speeds range from 0.2 to $1 \mathrm{~m} / \mathrm{min}$, with wire feed speeds of up to 10 times the welding speeds.

The welds produced by LBW show extreme aspect ratios (Fig. 1). The number of welding passes depends on the welding speed, the achievable melting rate, and the material to be joined. As a common feature, only one weld bead per weld was used in these studies. Thus, the scalability of the welding processes is limited because the safe joining cannot be guaranteed for very large gap widths, which would result in lack of fusions to the sidewalls.

One process variation according to process approach (I) is the Laser-MPNG welding. It was introduced by [7] at the Fraunhofer IWS as a novel welding process for the production of thick-walled components and was further developed, e.g., 


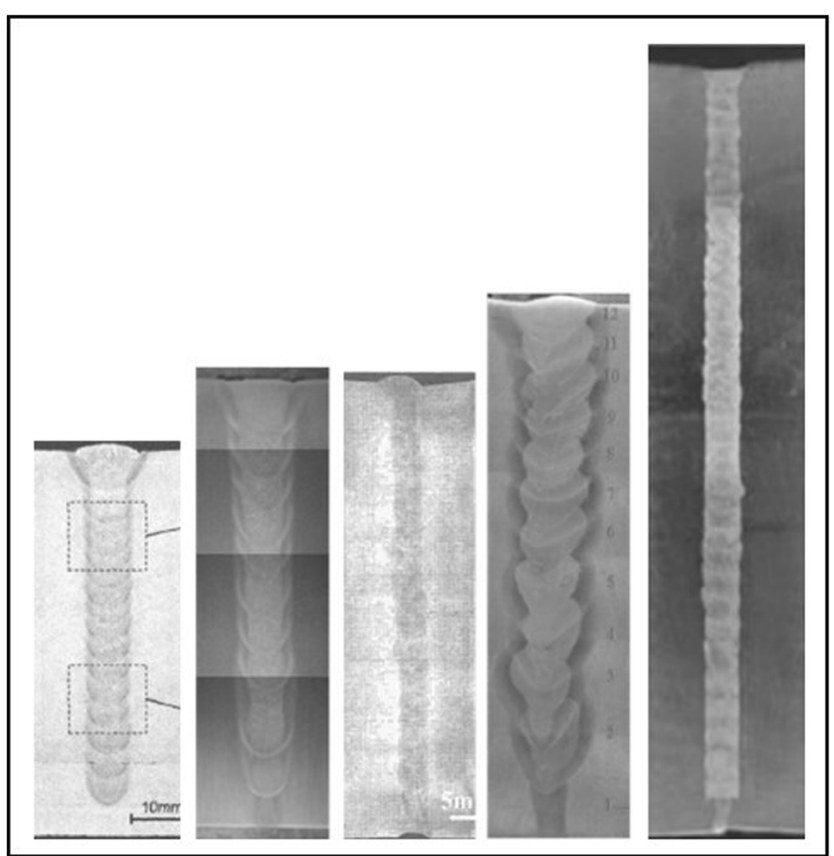

Fig. 1 Weld seams produced with multi-pass technology from left: [8, 19, 22-24]

by [3]. Figure 2 shows a selection of R\&D achievements in the field of Laser-MPNG at Fraunhofer IWS.

The welding process is characterized by its locally extremely concentrated energy input in the welding gap. This results in a minimal thermal influence of the parts to be joined, characterized by low component distortions and structural influences. Additionally, the weld seam volume by LaserMPNG is drastically reduced by minimal gap opening angles and root bar widths, resulting in minimal consumption of expensive filler metal. Due to these specific characteristics, the welding process is particularly suitable for materials that are difficult to weld and cost-intensive, such as nickel superalloys, which tend to develop hot cracks or strongly reduced hightemperature properties when the energy input is too high. The welding approach is as follows (Fig. 3):

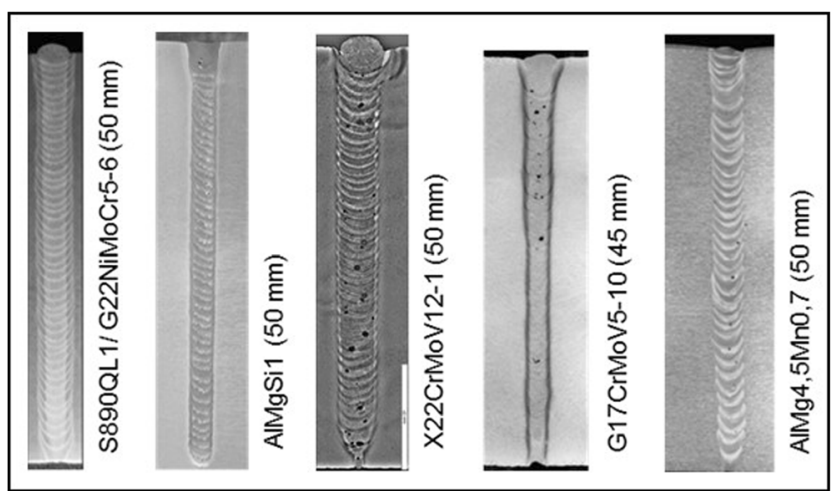

Fig. 2 Selection of Laser-MPNG welded joints realized under lab conditions at Fraunhofer IWS
(a)Seam preparation in the form of a V- or U-shaped groove

(b)Welding of the root passes with a static laser beam

$(\mathrm{c}+\mathrm{d})$ Welding the filling passes by introducing and melting filler wire material into the joining gap and the joining partners utilizing laser beam oscillation

Laser beam oscillation demands additional optics into the beam path. Therefore, galvanometer scanner is applicable. That implicates that the number of welding parameters is expanded by parameters such as amplitude and frequency. As a result, there are more degrees of freedom for developing the welding process with respect to the material, but also higher demands on the operating personnel. Furthermore, the investment in equipment for companies that previously had no lasers integrated in their production is relatively high. Topics such as laser protection equipment must be considered when deciding on this specific welding process.

A suitable field of application are modern fossil power plants where materials with a high risk of hot cracking, e.g., nickel superalloys, have to be joined. Hot cracks, which by definition occur during welding, can develop in the form of solidification cracks in the weld metal and/or, especially in the case of multi-pass welding, in the form of liquation cracks at the grain boundaries in the heat-affected zone of the weld seam and reduce the strength and high-temperature properties of the weld seam. Therefore, the focus was on joining Alloy $617 \mathrm{occ}$, a derivate from the well-known Alloy 617, with wall thicknesses up to $140 \mathrm{~mm}$. Alloy 617 and its derivate are solid solution strengthening nickel superalloys, which were developed for use in power plants in components such as piping or rotor shafts [2]. Alloy 617 is known for a relative good weldability compared to other nickel-based alloys, but especially in multi-pass weld seams, it shows hot cracking in the form of liquation cracking [18], even if the heat input per unit length is reduced compared to conventional welding technologies [5] (see Fig. 4).

In the work of [16], the welding of Alloy 617 with a fiber laser also shows liquation cracks, despite the very low heat input in the HAZ (Fig. 5). Therefore, the research focus was not only placed on the general proof of feasibility but in particular on the microstructure and properties of the weld.

\section{Test material-Alloy 617 occ}

The welding tests were carried out on the material alloy $\mathrm{NiCr} 23 \mathrm{Co} 12 \mathrm{MoB}$ with optimized chemical composition according to VdTÜV material sheet 573-Alloy 617 occ [21]. The sample material used was provided in the frame of the research project "ENCIO" (European Network for Components Integration and Optimization [6]). It was produced by vacuum induction melting and vacuum arc remelting (VIM+VAR), and it was available in the form of 


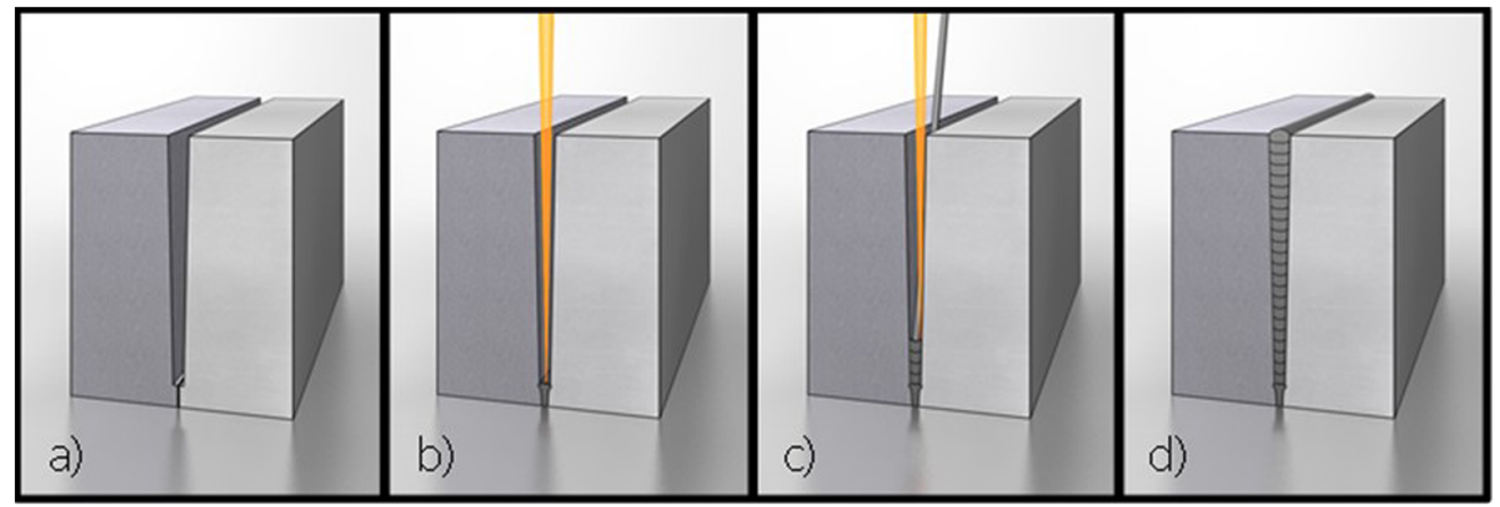

Fig. 3 Schematic diagrams of the Laser-MPNG welding process

pipes with different dimensions in solution annealed $\left(1160^{\circ} \mathrm{C} /\right.$ 1h) condition. The main part of the process development was carried out on material with the chemical composition listed in Table 1.

Figure 6 shows the microstructure of the base material in the form of a light microscopic image. The base material shows a pronounced microstructure bonding with areas of coarser grains $(>100 \mu \mathrm{m})$ and areas of smaller grains $(<100$ $\mu \mathrm{m})$. The areas with finer grains are richer in carbides, which prevents grain growth during solution annealing. According to ASTM classification, grain size ranges from 3 to 4 .

\section{Experimental procedure}

\subsection{Welding test}

The welding tests were carried out with the special welding head prototype remoweld®MPNG (Fig. 7) developed for the Laser-MPNG. The laser beam source used was a fiber laser from IPG YLR 4000 with a maximum laser beam power of 4 $\mathrm{kW}$. The fiber diameter was $50 \mu \mathrm{m}$, the collimation focal length was $85 \mathrm{~mm}$, and the focal length was $500 \mathrm{~mm}$, resulting in a laser beam focus diameter of $\sim 300 \mu \mathrm{m}$. The optical setup was configured to avoid any interaction of the laser beam with the component upper edges according to the used weld seam preparation in Fig. 9, despite the laser beam oscillation. The laser beam oscillation itself, overlaid on the welding feed, was performed using a 2D galvanometer scanner (welDYNA) from Scanlab GmbH corresponding to the oscillation described in equation 1 . All welding tests were carried out using a $\varnothing 1.2-\mathrm{mm}$ wire filler metal $\mathrm{NiCr} 22 \mathrm{Co} 12 \mathrm{Mo} 9$ (EN ISO 18274-S Ni 6617; Table 2) from BöhlerWelding experiments were performed in forehand welding mode (Fig. 8).

$$
\left(\frac{x_{\text {Laser }}(t)}{y_{\text {Laser }}(t)}\right)=\left(\frac{a_{X} \sin \left(2 \pi f_{X} t+\Delta \varphi\right)}{a_{Y} \sin \left(2 \pi f_{Y} t+\Delta \varphi\right)}\right),
$$

where $a_{x}$ is the amplitude in weld direction, $a_{y}$ is the amplitude transversal to weld direction, $f_{x}$ is the oscillation frequency in weld direction, $f_{y}$ is the oscillation frequency transversal to weld direction, and $\Delta \varphi$ is the phase shift.

\subsection{Calculations}

The calculation of the energy intensity was based on the trajectory of the laser beam overlaid with a harmonic oscillation and the intensity distribution of a multimode laser beam in the welding plane simulated according to the procedure described in [13].

The energy per unit length was calculated according to equation 2 .
Fig. 4 Liquation cracking in the HAZ of a weld seam produced by modified dip arc welding and a used energy per unit length of $2.9-4.7 \mathrm{~kJ} / \mathrm{cm}$ [5]
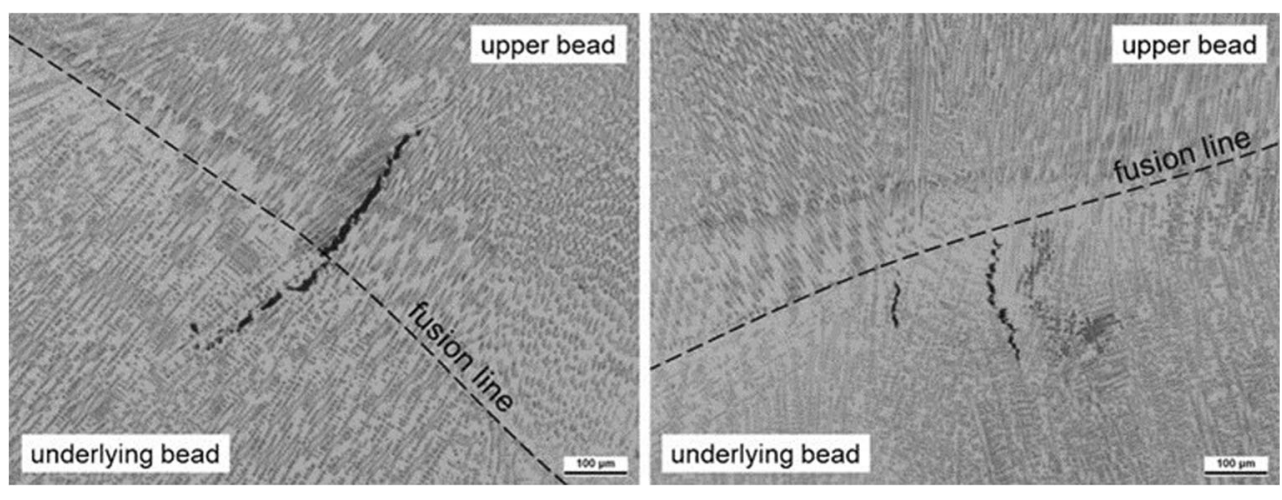
Fig. 5 Liquation cracking in the HAZ of a standard laser beam weld seam with an energy per unit length of $1.4 \mathrm{~kJ} / \mathrm{cm}[16]$
$E_{S}\left[\frac{\mathrm{kJ}}{\mathrm{cm}}\right]=\frac{P_{L}[\mathrm{~kW}]}{v_{s}\left[\frac{\mathrm{cm}}{\mathrm{s}}\right]}$,

where $E_{s}$ is the energy per unit length, $v_{s}$ is the welding speed, and $P_{L}$ is the laser beam power.

\subsection{Determination of metallurgical characteristics and mechanical properties}

Section preparation was done using different etchants: V2A pickling $\left(50^{\circ} \mathrm{C}\right)$, Kalling II, and Beraha III (color etching). The hardness test was determined on a fully automatic machine from LECO according to DIN EN ISO 6507-1:2018 according to Vickers with HV0.1.

Low-cycle-fatigue tests (LCF tests) were performed to determine cyclic strength at $700{ }^{\circ} \mathrm{C}$. The initial condition of the specimens was solution annealed $\left(1030^{\circ} \mathrm{C}\right)$ as well as stabilized annealed $\left(980^{\circ} \mathrm{C} / 3 \mathrm{~h}\right)$. The test was performed in accordance with ISO 12106:2003 on an electromechanical universal testing machine with an elongation ratio of $R=-1$ and an elongation rate of $6 \% /$ min until cracking (5\% load drop at maximum load).

Creep tests were carried out to determine the creep strength. The creep rupture tests were carried out in accordance with DIN EN ISO 204:2009 at $700{ }^{\circ} \mathrm{C}$. Specimens were tested in the stable annealed condition at 3 load levels at 225 , 250, and $287 \mathrm{MPa}$ until fracture.

\section{Results and discussion}

Welding a sample with a wall thickness of $140 \mathrm{~mm}$ required a continuous adaptation of the welding parameters due to the changing gap dimensions over height. In particular, the laser beam power, the oscillation amplitude across the welding direction, and the travel speeds had to be adjusted during the experiments. The adaption was performed by hand and pass by pass based on the process investigations from prior work from the author [12]. The used process parameter ranges for welding from root to top pass position are specified in Table 3 . The oscillation strategy played an outstanding role in the realization of a quality-compliant weld. As already mentioned, only process variants with one weld bead per pass are commercially used so far. In the present application, it was necessary to work with the 2-weld bead per pass technique. In the lower seam area from 140 to approx. $35 \mathrm{~mm}$ of seam depth, work was also carried out with one bead per pass by increasing the oscillation amplitude from 0.5 to $3 \mathrm{~mm}$. Subsequently, the amplitude was reduced to $1.6 \mathrm{~mm}$, and 2 weld beads next to each other were produced in a welding depth of around $25 \mathrm{~mm}$. By using this strategy, lack of fusions could be avoided very effectively.

The exact oscillation strategy and pattern used are shown in Fig. 9. Figure 9 (right) also shows the energy intensities of the individual passes and passes due to the welding parameters used. The maximum energy intensities at the inflection points of the oscillation patterns at the seam flanks never reached more than $\sim 500 \mathrm{~J} / \mathrm{mm}^{2}$ to avoid liquation cracks. The energy per unit length increased from $\sim 1 \mathrm{~kJ} / \mathrm{cm}$ in the root to $5 \mathrm{~kJ} / \mathrm{cm}$ in the upper passes.

Table 1 Chemical composition of the alloy batch Alloy 617 occ in percent by weight

\begin{tabular}{lllllllllllllllll}
\hline $\mathrm{Ni}$ & $\mathrm{Cr}$ & $\mathrm{Co}$ & $\mathrm{Mo}$ & $\mathrm{B}$ & $\mathrm{Nb}$ & $\mathrm{V}$ & $\mathrm{Ti}$ & $\mathrm{C}$ & $\mathrm{Al}$ & $\mathrm{Cu}$ & $\mathrm{Fe}$ & $\mathrm{Mn}$ & $\mathrm{P}$ & $\mathrm{S}$ & $\mathrm{Si}$ \\
\hline 54.3 & 22.0 & 11.7 & 8.4 & 0.003 & 0.19 & 0.4 & 0.4 & 0.05 & 1 & 0.01 & 1.10 & 0.35 & - & 0.002 & 0.07 \\
\hline
\end{tabular}


Fig. 6 Left: cross section of the pipe; right: longitudinal cut
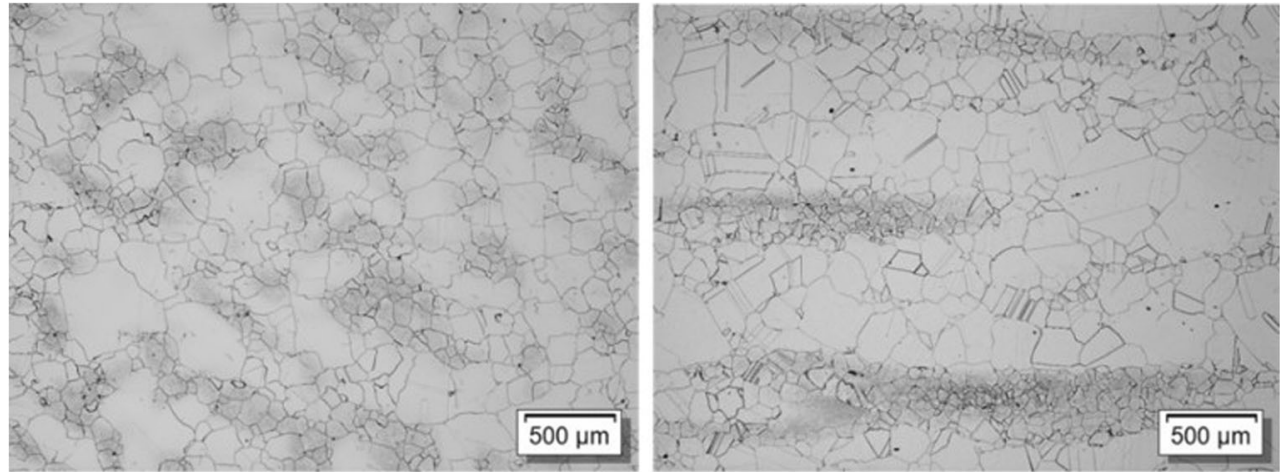

Finally, an Alloy 617 occ pipe element with a thickness of $140 \mathrm{~mm}$ was successfully welded using Laser-MPNG (Fig. 10 , left). The weld seam does not show any cracks or lack of fusions and reveals only low porosity $(<2 \%$ of the crosssection area).

Furthermore, the weld seam does not show any loss of alloying elements neither in the HAZ nor in the weld metal, which could result in reduced high-temperature properties (Fig. 11).

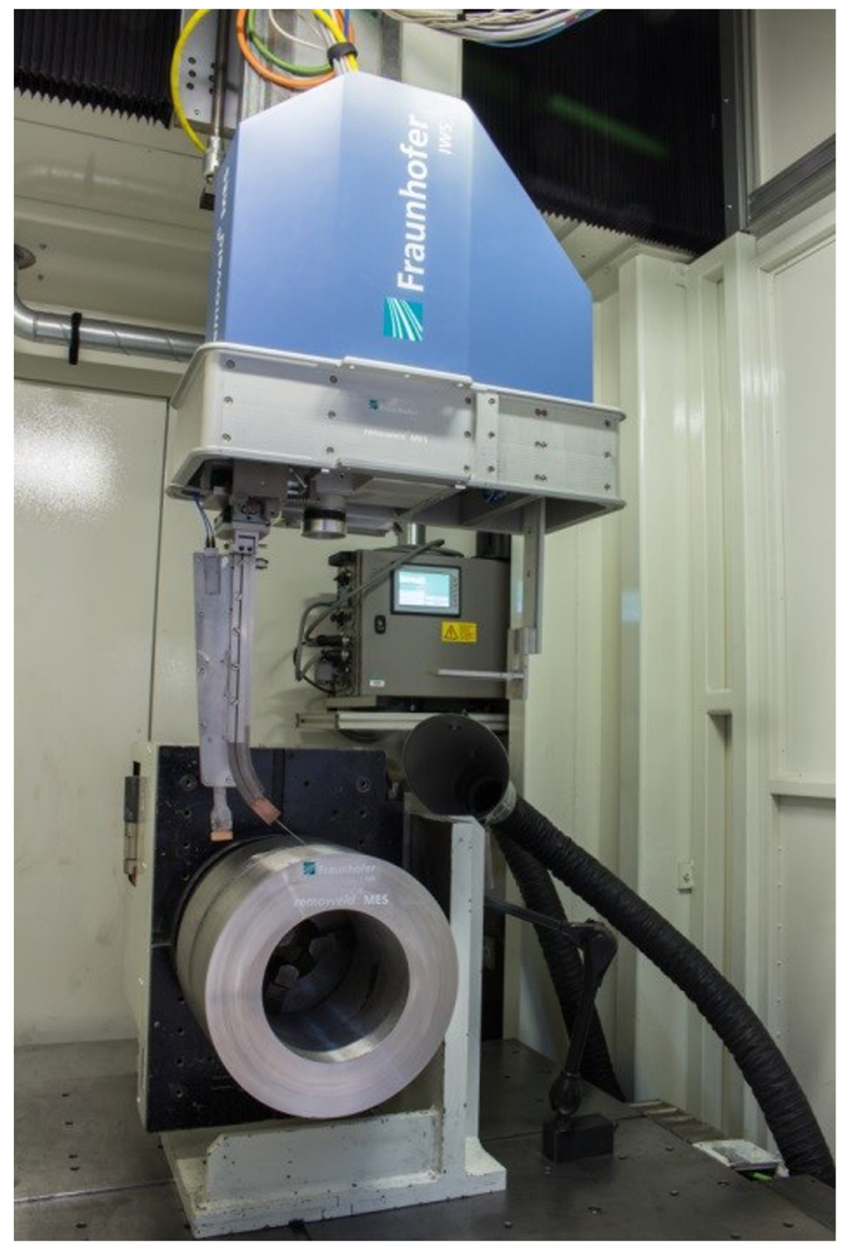

Fig. 7 remoweld®MPNG weld head prototype [11]
The increase in hardness is largely determined by the carbides precipitating at the grain boundaries in the HAZ and in the weld metal. The measurement of the hardness in 3 different welding positions is shown in Fig. 12. The figure shows that the transverse hardness curves are similar in the root, the weld seam center, and top. The hardness increases from values of approx. 200-220 HV0.1 to 300-330 HV0.1. Differences result from the fact that higher energies per unit length are used in the upper welding passes. However, heat treatment of the specimens generally leads to a homogenization, which means that a homogeneous precipitation of carbides is set both in the grain inner and at the grain boundaries, and as a result, the locally higher hardness of the weld drops to the level of the base metal $[11,12]$.

\section{Microstructure of the weld seams}

Figure 13 shows a coarse-grained weld microstructure with fine dendritic solidification and segregation effects (molybdenum enrichment) appearing in interdendritic regions after welding without a post weld heat treatment. Also, very fine spherical precipitates in the form of Al-oxides and Ti-nitrides (I, see Fig. 13, right) and Mo-rich carbides (II, see Fig. 13, right) could be observed via EDX analyses in SEM. The aluminum oxides are most likely formed because complete shielding gas coverage was not provided in the process zone. The carbides, both Morich and Cr-rich, result from the interaction of the alloying elements in the base metal and filler metal.

The HAZ is very small $(\sim 1 \mathrm{~mm})$ and can be divided into two parts (Fig. 14):

Table 2 Typical chemical composition of $\mathrm{NiCr} 22 \mathrm{Co} 12 \mathrm{Mo} 9$ in percent by weight [14]

\begin{tabular}{llllllllll}
\hline $\mathrm{Ni}$ & $\mathrm{Cr}$ & $\mathrm{Co}$ & $\mathrm{Mo}$ & $\mathrm{Ti}$ & $\mathrm{C}$ & $\mathrm{Al}$ & $\mathrm{Fe}$ & $\mathrm{Mn}$ & $\mathrm{Si}$ \\
\hline Bal. & 21.8 & 11 & 9 & 0.3 & 0.06 & 1.3 & $<0.5$ & 0.1 & 0.1 \\
\hline
\end{tabular}




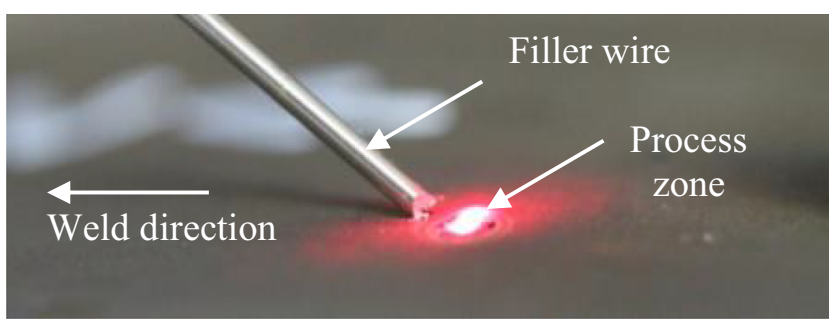

Fig. 8 Image of the forehand welding configuration used in this study

I. Hardly visible grain boundaries through dissolution of carbides at the grain

II. Greater prominence of grain boundaries characterized by carbides

And the weld metal has an epitaxial and flawless growth to the base material. In zone I of the HAZ, temperatures were above $1100{ }^{\circ} \mathrm{C}$ which are reached for a short time. At this temperature, the material undergoes solution annealing in its initial state. It can therefore be assumed that the temperature regime in HAZ I leads to a kind of local solution annealing of the carbides. In HAZ II, on the other hand, the temperatures are already lower (greater distance from the solidification line). It is assumed that the temperature here does not reach $1100{ }^{\circ} \mathrm{C}$, but is above $980{ }^{\circ} \mathrm{C}$. This temperature is used for stable annealing of the material in order to selectively precipitate carbides at the grain boundaries and thus increase the creep strength in service. For this reason, the carbides grow at the grain boundaries of the HAZ II.

After the mentioned commonly used post weld heat treatment (PWHT) at $980^{\circ} \mathrm{C}$ for $3 \mathrm{~h}$, the $\mathrm{HAZ}$ is hardly recognizable in comparison with the unannealed sample. That means that carbides have precipitated again, and between the heat-affected base material and weld material, only a very thin low carbide zone (approx. $5 \mu \mathrm{m}$ ) could be found. The weld metal changed as well, and Mo- and Cr-rich carbides were formed out of formerly Mo-rich segregation areas (Fig. 15).

\section{Mechanical properties}

To qualify the Laser-MPNG, transfer weld specimens were taken from 3 welds (SN010, SN017, and SN024). The high-temperature properties were investigated at $700{ }^{\circ} \mathrm{C}$, which is one of the requirements in future power plants. The results of the study were used to determine the quality of the Laser-MPNG welds. Figure 16 shows a comparison of the results from

Table 3 Experimental parameters

\begin{tabular}{llll}
\hline Laser power & Welding speed & Wire feed rate & Oscillation amplitude across the welding direction \\
\hline$[\mathrm{kW}]$ & {$[\mathrm{m} / \mathrm{min}]$} & {$[\mathrm{m} / \mathrm{min}]$} & {$[\mathrm{mm}]$} \\
$2-4$ & $0.5-1$ & $1-3$ & $0.5-3$ \\
\hline
\end{tabular}
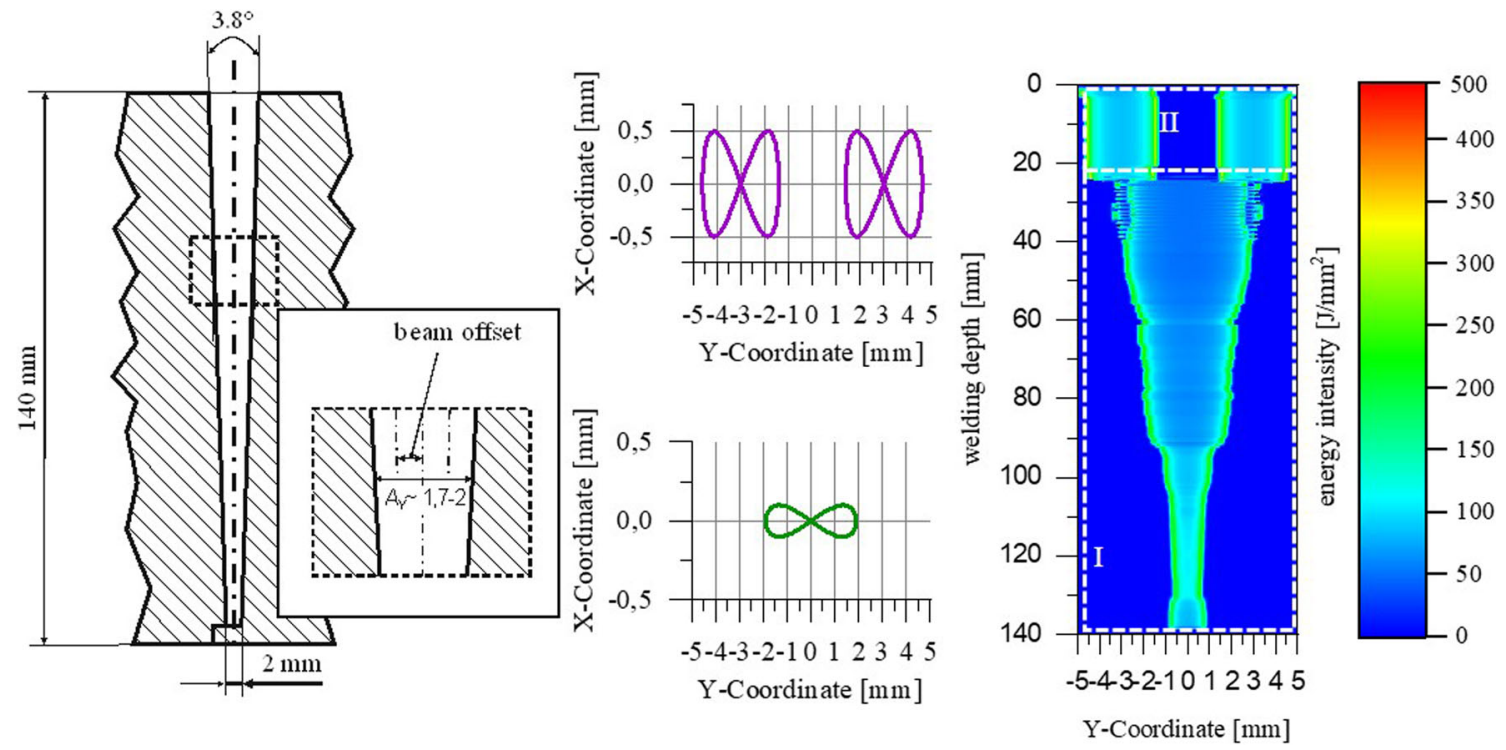

Fig. 9 Left: weld seam preparation; right: oscillation strategy of Laser-MPNG with $140 \mathrm{~mm}$ wall thickness 

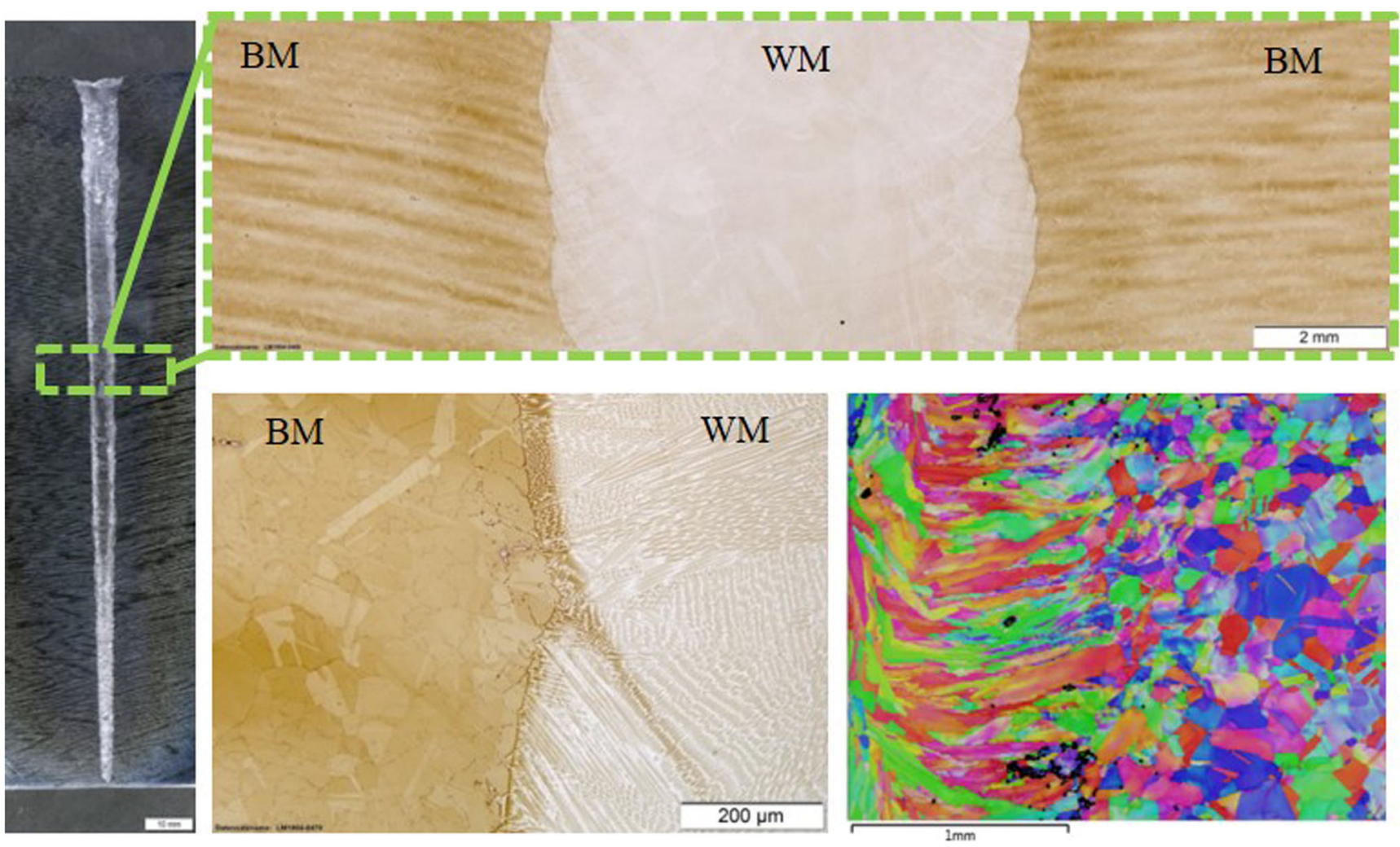

Fig. 10 Laser-MPNG weld seam with $140 \mathrm{~mm}$ welding depth and detailed views of the weld seam built up and HAZ and an EBSD-Analysis (BM base material, WM weld metal)

LCF tests with a load rate of $6 \% /$ min on base material and Laser-MPNG specimens before and after stabilizing heat treatment $\left(980^{\circ} \mathrm{C} / 3 \mathrm{~h}\right)$. The base material shows very good fatigue behaviour slightly above the existing scatter band from [9].

The Laser-MPNG specimens fit into the existing scatter band except for one specimen, even though some welding defects led to cracks in the weld metal or in the HAZ. Weld defects as crack initiators or crack accelerators were aluminum oxide inclusions and lack of fusions to the sidewall or between the passes. In the case of the SN024-P6 specimen, a welding defect in the form of a lack of fusion to the sidewall was already visible on the surface of the specimen after specimen preparation (Fig. 17), which is the reason for the comparatively short service life. A systematic influence of the stabilizing heat treatment on the LCF service life is not discernible.

In Fig. 18, the results of the $700{ }^{\circ} \mathrm{C}$ creep tests on base material and Laser-MPNG specimens taken from sample
Fig. 11 Weld seam without heat treatment-EDX line scan: base material-HAZ-weld metal

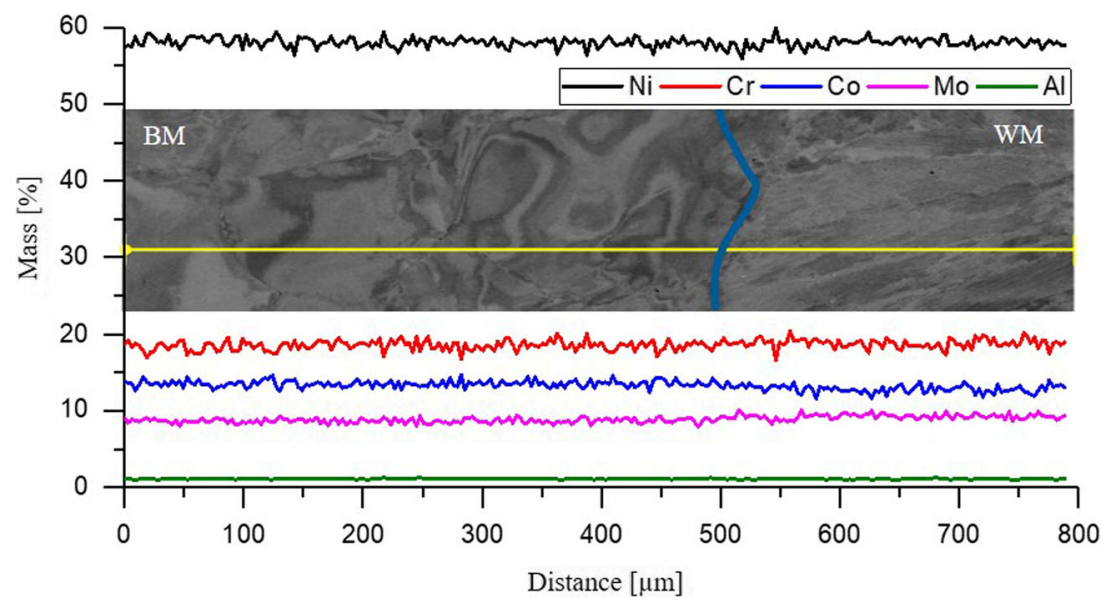



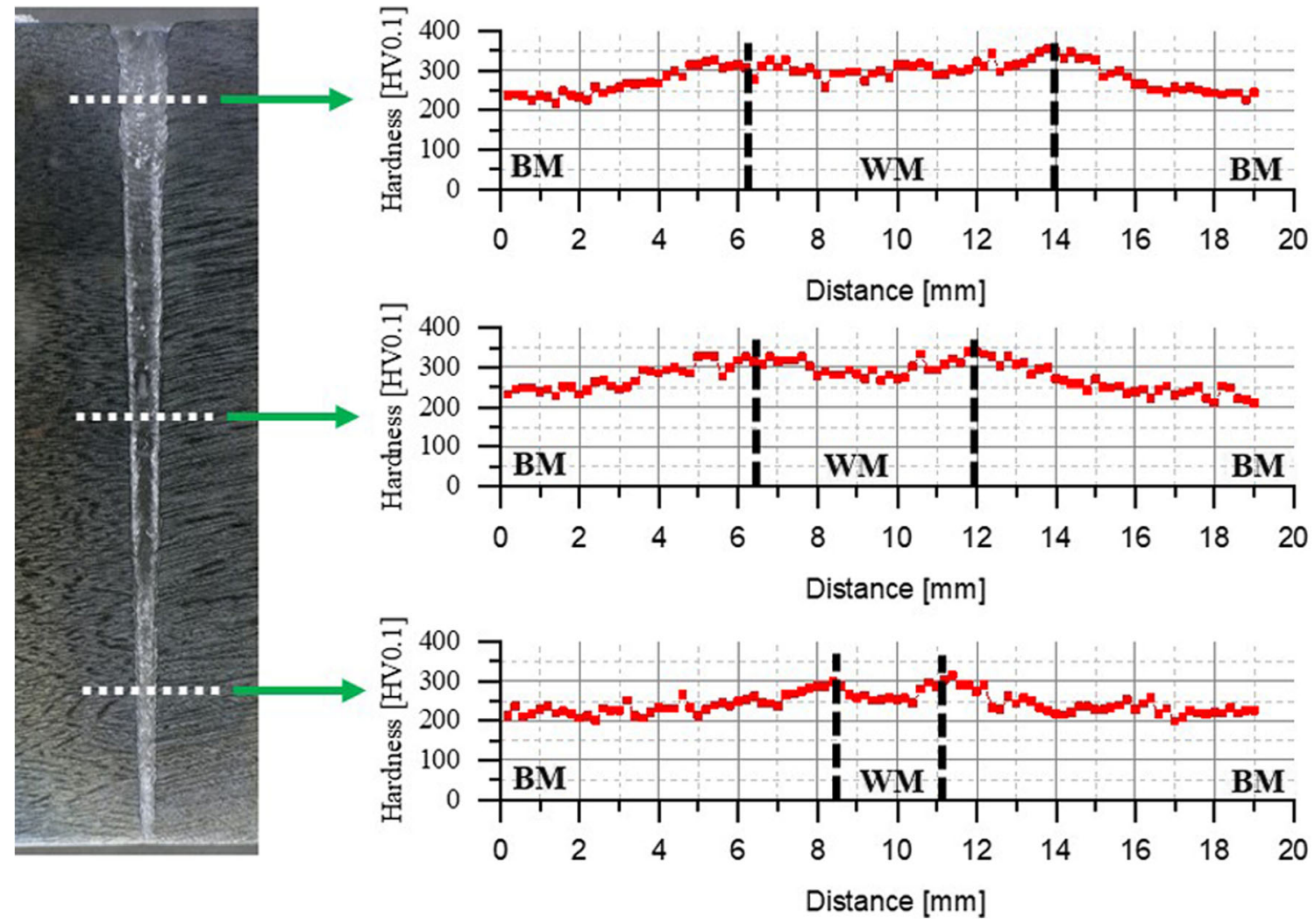

Fig. 12 Hardness transversal profiles in the 3 different seam areas
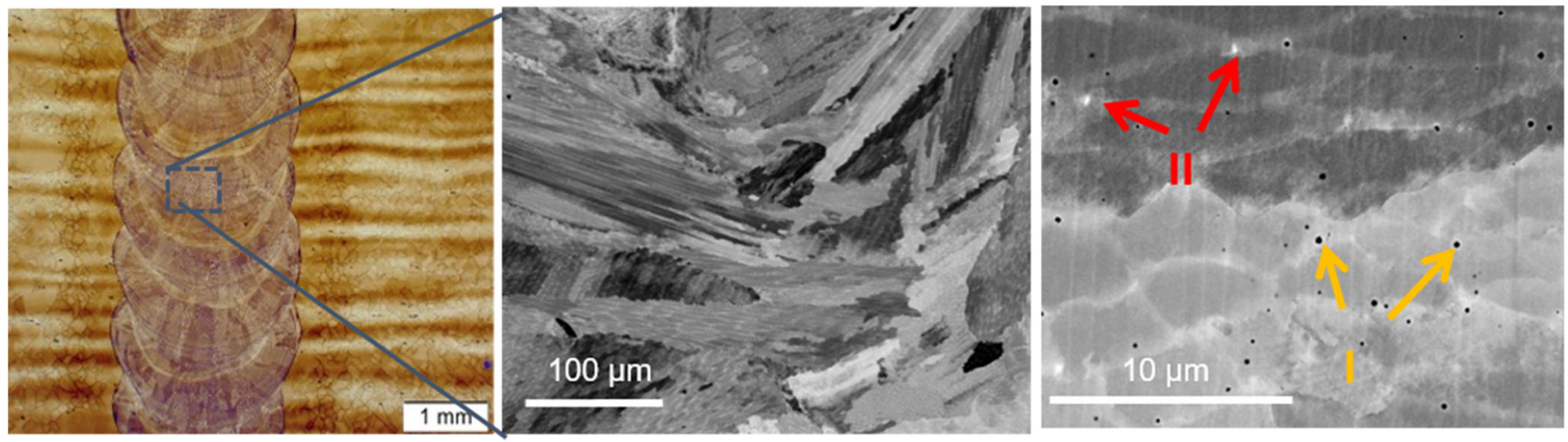

Fig. 13 Left: weld seam without heat treatment; center: SEM image to illustrate the dendritic solidification structure; right: detailed SEM image of the weld structure with precipitates
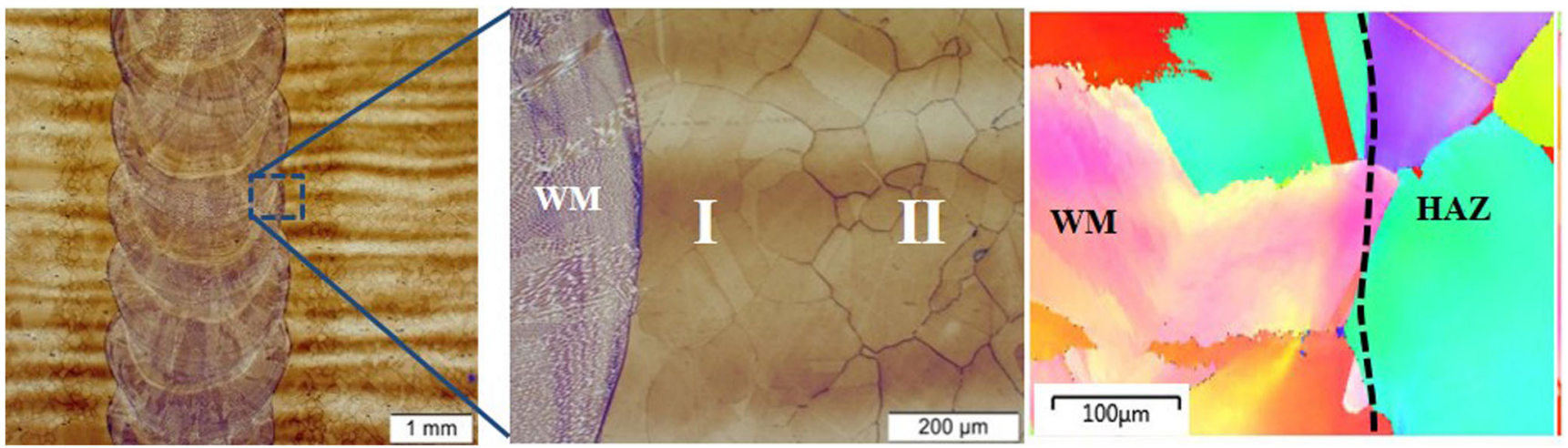

Fig. 14 Left: weld seam without heat treatment; center: REM detail view of the HAZ; right: EBSD image illustrating epitaxial microstructural growth [1] 


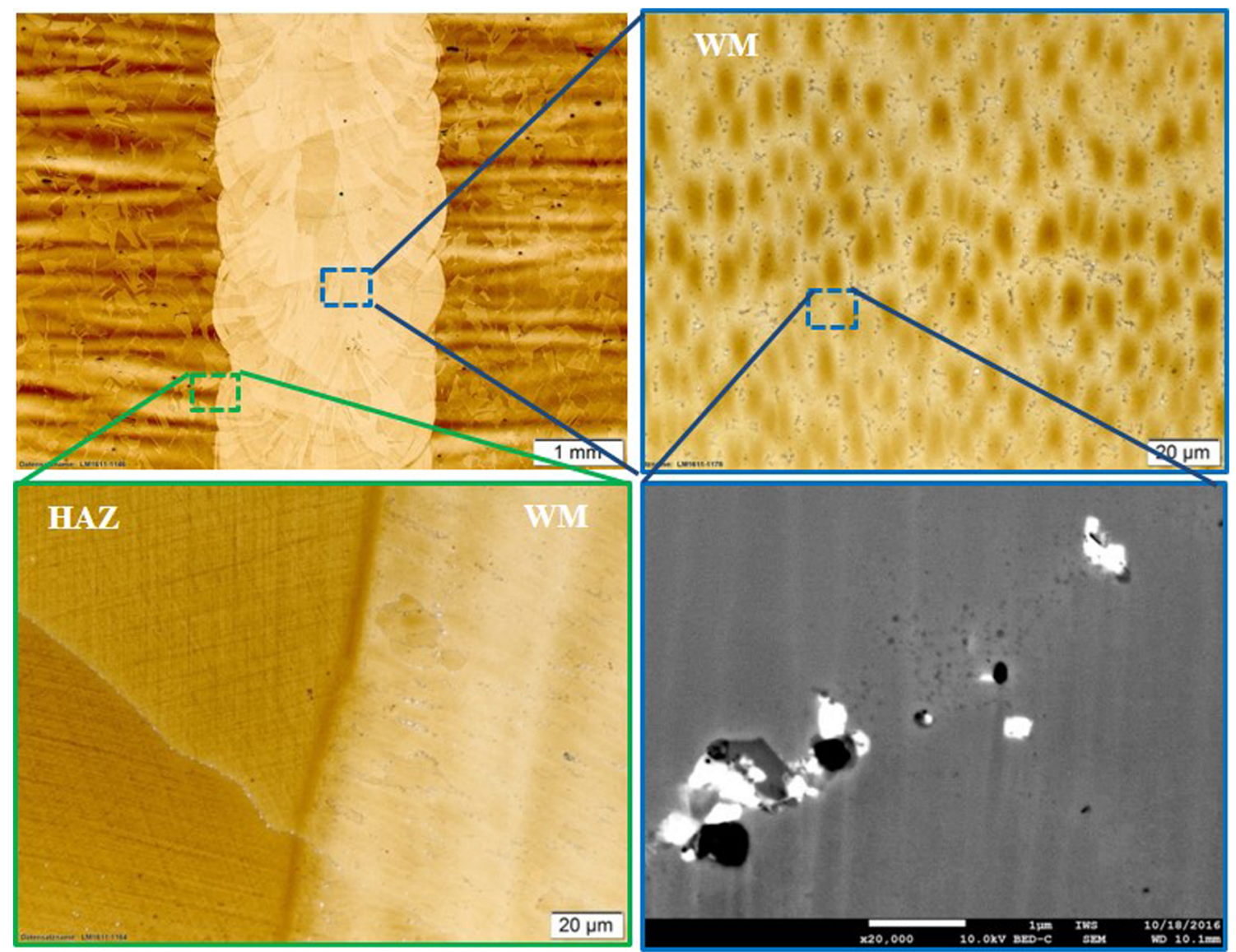

Fig. 15 Top left: weld seam stabilization annealing $\left(980^{\circ} \mathrm{C} / 3 \mathrm{~h}\right)$; top right: detailed view of the weld seam structure; bottom left: detailed view of the HAZ, fusion line, and weld seam structure; bottom right: SEM detailed view of the precipitated carbides in the weld metal

SN017 are compared to available data on Alloy 617B material from literature. The Laser-MPNG specimens were subjected to stable annealing at $980{ }^{\circ} \mathrm{C} / 3 \mathrm{~h}$ before the start of the test, while the base material was tested in the solution-annealed initial condition. The base material and the Laser-MPNG samples fit into the present European Creep Collaboration Committee (ECCC) scatter band of the material Alloy 617B [4]. All 3 specimens with weld seam failed in the base material, probably due to the locally higher strength of the weld due to the precipitation
Fig. 16 Comparison of LCF properties of base material and Laser-MPNG samples [11]

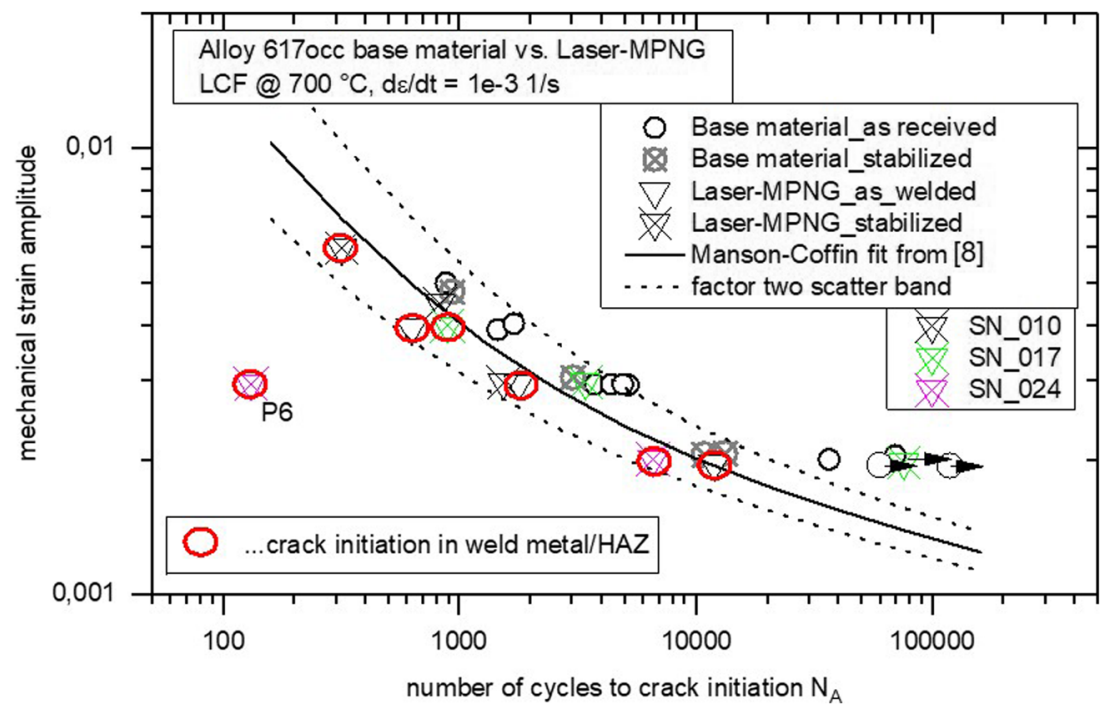




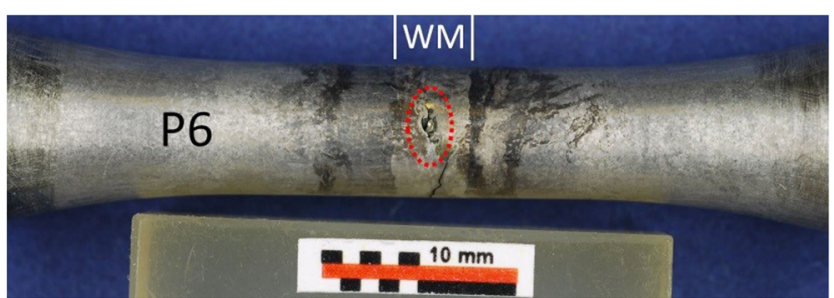

Fig. 17 Laser-MPNG sample P6 with a weld defect in the form of a lack of fusion to the sidewall as a crack initiator [11]

morphology of the carbides inside the grain and at the grain boundaries, which were investigated in more detail below for a creep test specimen.

Figure 19 shows the Laser-MPNG sample SN017-16 $\left(700^{\circ} \mathrm{C} / 225 \mathrm{MPa}\right)$ and two cross sections from the sample after creep rupture. The material necking of the sample occurs only in the base material, and the failure mode is intergranular. The weld seam shows just a few very small defects (up to 200 $\mu \mathrm{m})$ in the HAZ which propagate from the HAZ into the weld seam (Fig. 20).

A detailed view at the microstructure of the different sample areas (weld metal, HAZ, base material with thermal, and mechanical loading (BM1, close to the fracture surface) and base material with thermal loading (BM2, clamping)) is shown in Fig. 21. The precipitates present were determined by EDX analyses in SEM with the following result: at the grain boundaries of all sample areas, Cr-carbides (I) and Mo-rich carbides (II) can be found. The Cr-rich carbides can also be found inside the grains of the BM2. The weld metal also shows a pronounced precipitation of the $\mathrm{Cr}$-rich and Mo-rich carbides, as well as Al-oxides and Ti-nitrides (III). The BM 1 shows no precipitates in the grain inside and after evaluation of the TEM micrographs. It can be assumed that precipitate-free areas have developed at the grain boundaries (see Fig. 21, bottom right, red arrows) due to the thermal and mechanical stress and that these locally reduce the grain boundary strength. Thus, the creep strength and for this reason the crack initiation and fracture take place in the base material.

\section{Summary}

- Laser-MPNG was used for the first time to produce weld seams up to $140 \mathrm{~mm}$ in depth; they were free of cracks and lack of fusions and showed low porosity $(<2 \%$ of the cross-section area).
Fig. 18 Laser-MPNG samples in the $700{ }^{\circ} \mathrm{C}$ creep rupture diagram for $\mathrm{A} 617 \mathrm{~B} / \mathrm{occ}$ [20]

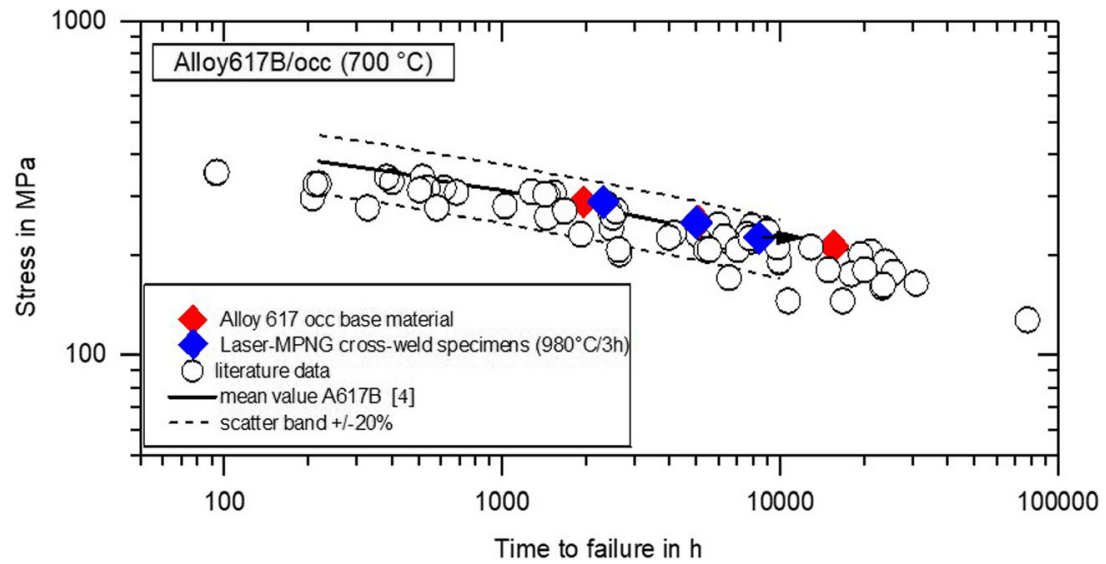

Time to failure in $\mathrm{h}$

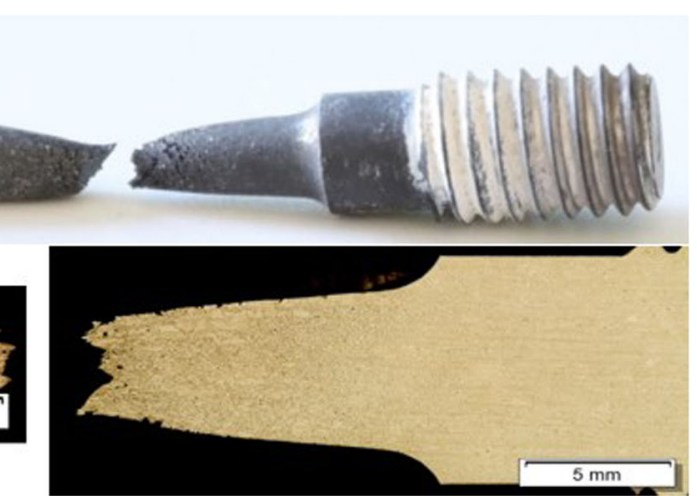

Fig. 19 Laser-MPNG sample SN017-16 $\left(700^{\circ} \mathrm{C} / 225 \mathrm{MPa} /\right.$ time to failure= $\left.9947 \mathrm{~h}\right)$ with creep fracture in the base material 

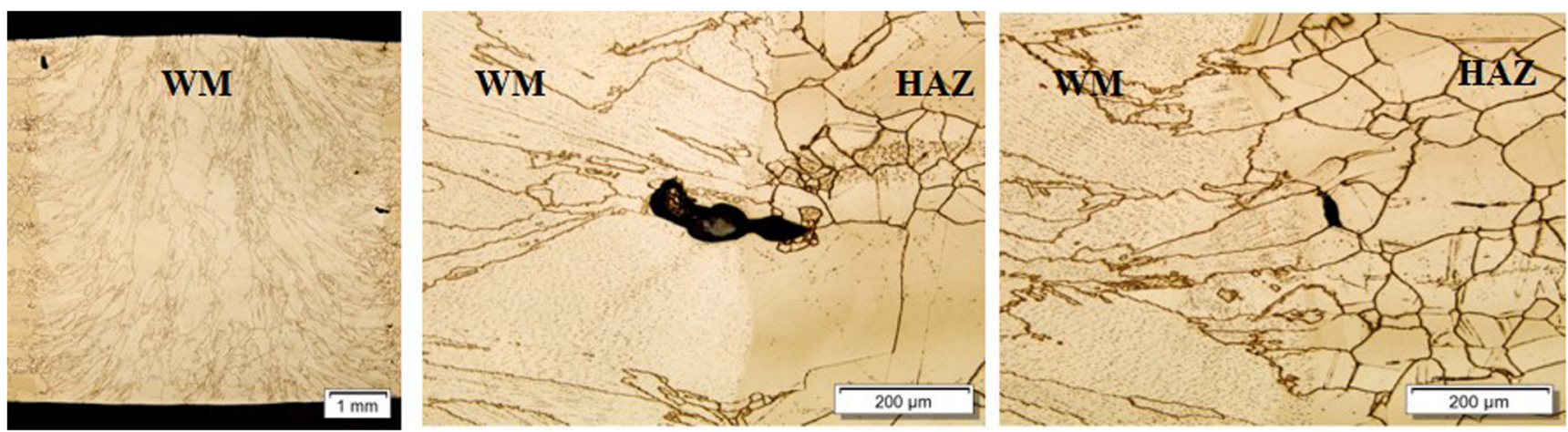

Fig. 20 Laser-MPNG sample SN017-16 $\left(700^{\circ} \mathrm{C} / 225 \mathrm{MPa} /\right.$ time to failure= $\left.9947 \mathrm{~h}\right)$ detailed view on the weld seam and $\mathrm{HAZ}$ after creep rupture test

- A key factor for ensuring the weld seam quality is the laser beam oscillation for safe melting of the joining partners and the filler material.

- The thermal influence of the base material during laser beam welding is very low. Accordingly, the width of the HAZ is very small $(\sim 1 \mathrm{~mm})$. After the PWHT, which is usually carried out, no microstructural differences between HAZ and base material are discernible.

- The use of the welding process does not lead to detrimental loss of alloying elements. The maximum energy per unit length used was $5 \mathrm{~kJ} / \mathrm{cm}$.

- The available Alloy 617 occ base material batch shows very good creep rupture and fatigue properties in comparison with available literature data of Alloy 617B.

- Laser-MPNG cross-weld specimens show identical creep strength with failure in the base material and only somewhat lower fatigue resistance compared to base material specimens.

\section{Conclusion}

Within the scope of the process investigations, extremely deep laser beam welding seams of $140 \mathrm{~mm}$ with very low energy per unit length and very low laser power could be demonstrated for the first time worldwide using Alloy 617 occ.

The development of Laser Multi-Pass Narrow-Gap welding is characterized in particular by the following:

- The idea and realization of a two-dimensional highfrequency beam deflection with an adjustable power density (depending on the selected oscillation

Fig. 21 Top left: weld metal; top right: HAZ; bottom left: base material with mechanical and thermal load (close to fracture surface); bottom right: base material with thermal load (clamping)
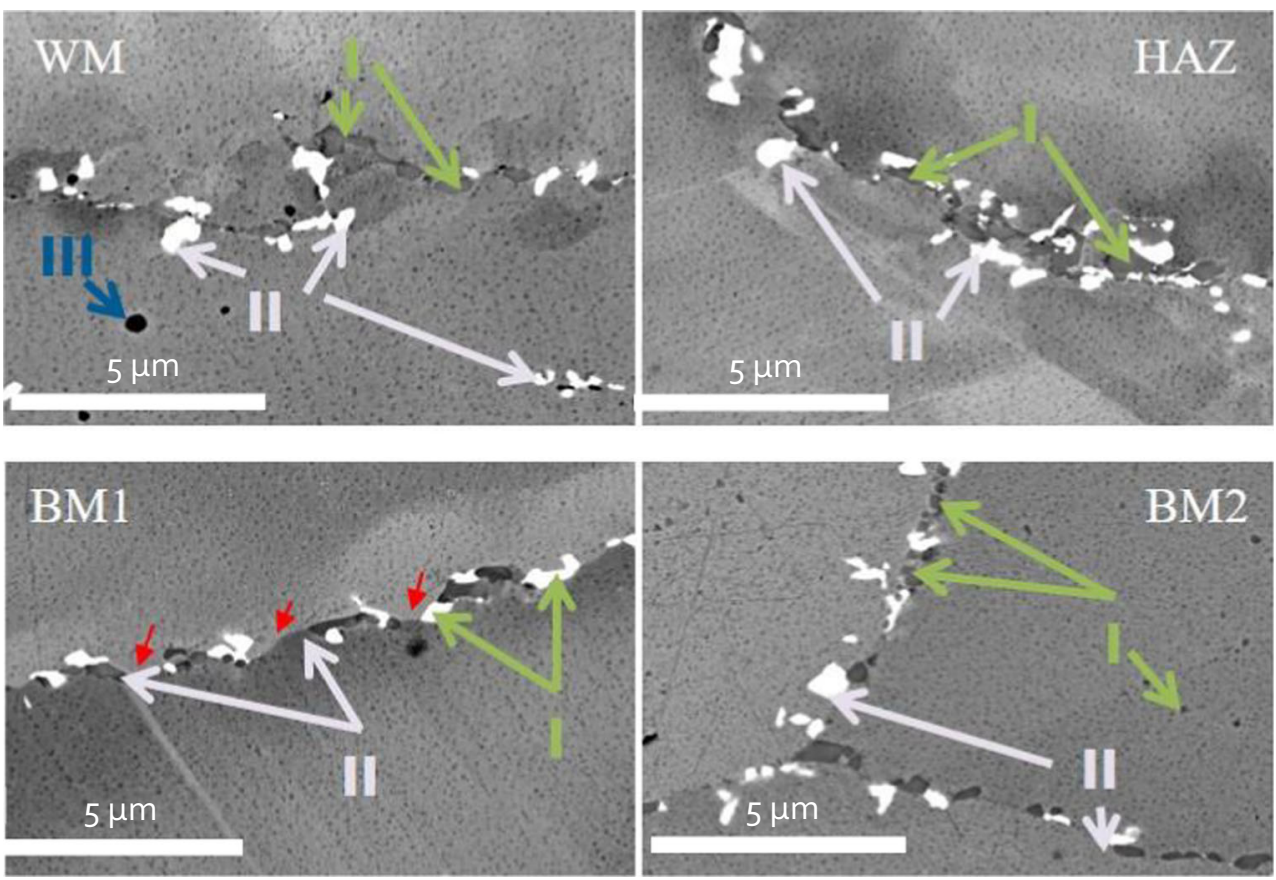
parameters) increase at the two seam flanks to ensure sidewall fusion

- The achievement of maximum oscillation frequencies by superimposing two harmonic oscillations in $x$ and $y$ directions in a suitable frequency ratio

- The achievement of sufficient local heating of the seam flanks to ensure wettability by the melt despite almost grazing incidence of the laser beam

- Optimization of the seam flank structure (height of individual passes, size of the weld pool in feed direction, safe melting and handling of the SZW, and avoidance of hot cracks and two weld beads per welding pass)

The Laser-MPNG process is particularly competitive where the added value of the components to be joined is high. The Laser-MPNG therefore has its advantages especially in areas where high precision, high quality, and high mechanical properties are required. But the technical use in areas where conventional welding processes do not cause any significant degradation of properties is to be discussed.

Furthermore, it should be noted that the technical understanding of the responsible welding personnel is an important prerequisite for professional execution of the Laser-MPNG welding process. The work contents and processes change drastically when using multi-kilowatt lasers compared to competing arc welding processes. Consequently, completely new demands are placed on the operating and safety personnel (laser protection).

In summary, it can be estimated that Laser-MPNG welding is currently the most flexible, property-conserving beam welding process that can be adapted to the material in the best possible way for producing welds of extremely high depth, and that further developments (e.g., "refinement" for steel construction applications) are now available for industrial applications

Acknowledgements The authors would like to thank all those involved for their support and especially the colleagues from Fraunhofer IWM Freiburg for performing the mechanical tests.

Code availability Not applicable

Author contribution Conceptualization: Benjamin Kessler; methodology: Benjamin Kessler and Dirk Dittrich; formal analysis and investigation: Benjamin Kessler and Dirk Dittrich; writing — original draft preparation: Benjamin Kessler; writing-review and editing: Dirk Dittrich, Jens Standfuss, and Christoph Leyens; funding acquisition: Berndt Brenner and Jens Standfuss; resources: Dirk Dittrich, Jens Standfuss, and Christoph Leyens; supervision: Jens Standfuss and Christoph Leyens

Funding Open Access funding enabled and organized by Projekt DEAL. The presented results were achieved due to a strategic partnership by involved Fraunhofer institutes IWS, Fraunhofer IWM, and Fraunhofer
IKTS and were supported by the Fraunhofer Internal Programs under Grant No. WISA 828505.

Data availability Data and material are stored at Fraunhofer IWS Dresden.

\section{Declarations}

Competing interests The authors declare no competing interests.

Open Access This article is licensed under a Creative Commons Attribution 4.0 International License, which permits use, sharing, adaptation, distribution and reproduction in any medium or format, as long as you give appropriate credit to the original author(s) and the source, provide a link to the Creative Commons licence, and indicate if changes were made. The images or other third party material in this article are included in the article's Creative Commons licence, unless indicated otherwise in a credit line to the material. If material is not included in the article's Creative Commons licence and your intended use is not permitted by statutory regulation or exceeds the permitted use, you will need to obtain permission directly from the copyright holder. To view a copy of this licence, visit http://creativecommons.org/licenses/by/4.0/.

\section{References}

1. Brenner B, Keßler B, Dittrich D, Maier G, Bendjus B. Laser Multi Pass Narrow Gap welding - a new technology for joining thick walled components of power stations. VGB-Workshop "Materials and Quality Assurance"; 18 and 19th May 2017, Maria Enzersdorf, Austria

2. Bürgel R (2011) Handbuch der Hochtemperatur-Werkstofftechnik, Vieweg+Teubner Verlag, Springer Fachmedien Wiesbaden GmbH

3. Dittrich D, Schedewy R, Brenner B, Beyer E (2015) LaserstrahlMehrlagen-Engstspaltschweißen zum verzugsarmen und heißrissfreien Fügen von Aluminiumlegierungen im Dickblechbereich. Schweißen Schneiden 3:114-117

4. European Creep Collaboration Committee (ECCC) Data Sheets 2017, Issue 2, Resistance

5. Fink C, Zinke M (2013) Welding of nickel-based alloy 617 using modified dip arc processes. Weld World 57:323-333

6. Di Gianfrancesco et al. ENCIO project: an European approach to $700^{\circ} \mathrm{C}$ power plant. Advances in Materials Technology for Fossil Power Plants; Proceedings from the 7th International Conference, October 22.-25.2013, Waikoloa, Hawaii, USA

7. Göbel G, Brenner B, Beyer E (2007) New application possibilities for fiber laser welding, Proc. of 26th ICALEO, USA

8. Guowei Z, Ronghsi X (2014) Ultra-narrow gap high power fiber laser beam welding of stainless Steel heavy section with filler wire. Chin J Lasers 41

9. Hüggenberg D, Speicher M, Zickler S, Klenk A, Maile K (2015) Forschungsvorhaben HWT II: Untersuchung des Betriebs- und Versagensverhaltens dickwandiger Bauteile für hocheffiziente Kraftwerke. Abschlussbericht zum BMWi-Forschungsvorhaben Förderkennzeichen: 03ET2017

10. Karhu M, Kujanpää V (2015) Defocusing techniques for multi-pass Laser welding of austenitic stainless Steel. Phys Procedia 78:53-64

11. Kessler B, Dittrich D, Brenner B, Standfuß J, Beyer E, Leyens C, Maier G (2019) Laser Multi-Pass Narrow-Gap welding - a promising technology for joining thick-walled components of future power plants; IIW 2018 - International Conference on Advanced 
Welding and Smart Fabrication Technologies; MATEC Web of Conferences 269, 02011

12. Kessler B, Dittrich D, Brenner B, Standfuß J, Beyer E, Leyens C (2019) Laser-multi-pass-narrow-gap-welding of nickel superalloy Alloy 617OCC. J Laser Appl 31:022412

13. Mahrle A, Beyer E (2007) Modelling and simulation of the energy deposition in laser beam welding with oscillatory beam deflection; In: Proceedings of the 26th Int. Congress on Application of Laser \& Electro-Optics ICALEO, Paper 1805, 714-723, USA, Orlando

14. N.N. (2010) Böhler NIBAS 617-IG Datasheet. voestalpine Böhler Welding Group GmbH

15. Näsström J, Frostvarg J, Kaplan AFH (2017) Multipass laser hotwire welding: morphology and process robustness. J Laser Appl 29(2)

16. Ren W, Lu F, Nie P, Yang R, Liu X, Feng K, Li Z (2015) Liquation cracking in fiber laser welded joints of inconel 617. J Mater Process Technol 226:214-220

17. Ren W, Lu F, Nie P, Yang R, Liu X, Feng K, Li Z (2017) Effects of the long-time thermal exposure on the microstructure and mechanical properties of laser weldings of Inconel 617. J Mater Process Technol 247:296-305

18. Siefert JA, Shingledecker JP, DuPont JN, David SA (2016) Weldability and weld performance of candidate nickel based superalloys for advanced ultrasupercritical fossil power plants part II: weldability and cross-weld creep performance. Sci Technol Weld Join 21(5):397-427
19. Tsukamoto T, Kawanaka H, Maeda Y (2011) Laser narrow gap welding of thick carbon steels using high brightness laser with beam oscillation, Proc. of 30th ICALEO, USA

20. Varfolomeev I, Maier G, Moroz S, Oesterlin, Keßler B. Einfluss von Eigenspannungen und fertigungsbedingten Defekten auf die Lebensdauer dickwandiger, Laser-geschweißter Rohre aus Alloy 617occ. Proceedings zur 51. Tagung des DVM-Arbeitskreises "Bruchmechanik und Bauteilsicherheit", 19.-20. Februar 2019, Aachen

21. VdTÜV-Werkstoffblatt 573 (2016) Hochwarmfeste NickelbasislegierungNiCr23Co12MoB; Werkstoff-Nr. 2.4673 Stab, Schmiedestück; Verband der TÜV e.V

22. Yamazaki Y, Abe Y, Hioki Y, Tanaka T, Nakatani M, Kitagawa A, Nakata K (2017) Development of narrow gap multi-layer welding process using oscillation laser beam. Weld Int 31:38-47

23. Yang W, Xin J, Fang C, Dau W, Wie J, Wu J, Song Y (2019) Microstructure and mechanical properties of ultra-narrow gap laser weld joint of $100 \mathrm{~mm}$-thick SUS304 steel plates. J Mater Process Technol 265:130-137

24. Zhao Y, Ma S, Huang J, Wu Y (2017) Narrow-gap laser welding using filler wire of thick steel plates. Int J Adv Manuf Technol 93: 2955-2962

Publisher's note Springer Nature remains neutral with regard to jurisdictional claims in published maps and institutional affiliations. 